\title{
Controversies in the Acute Management of High Spinal Cord Injuries, an Update and Opinion
}

\author{
Nabil A Alageli* \\ Consultant orthopaedic and spine surgeon, Tripoli Medical Centre, Libya
}

Received: October 19, 2017; Published: October 26, 2017

*Corresponding author: Nabil A Alageli, Consultant orthopaedic and spine surgeon, Tripoli Medical Centre, P0 Box 80596, Zawia Street Office Tripoli, Libya, Email: ageli@msn.com

\begin{abstract}
The incidence of spinal cord injuries is the lowest of all major trauma, with devastating impact on the individual affected. The immediate treatment, though it remains mainly supportive, in many situations will determine the outcome and the cost of health care. Standards of care are unfortunately still lacking, this is mainly due to the existing controversies and lack of effective treatment of the injured cord. The author discusses here some of the controversial points based on literature review and personal observation.
\end{abstract}

Abbreviations: MP: Methyl Prednisolone; NASCIS: National Acute spinal Cord Injuries Study; SDI: Spinal Decompression in Acute

\section{Introduction}

\section{Timing of surgery}

It is well known that secondary insult to the spinal cord may occur because of mechanical as well as physiological instability, an injured cord will exhibit a cascade of pathological processes involving immune mechanisms and mediators which will lead to swelling of the cord rendering it susceptible to iatrogenic injury including hypoxia and hypotension, this is found to be maximal at 24 hours. The argument for early surgery should mean that it is carried out within 4 hours of injury i.e. before cord swelling become apparent; complex, or lengthy surgery at the stage of spinal cord oedema could be harmful. Reports exist that outcome of surgery done at 24 to 72 hours is not associated with better neurological improvement or shorter length of stay in hospital, at the same time reported a high percentage of complications ranging between 24 to $41 \%$ [1-20].

It has to be noted that in cervical and upper thoracic cord injuries," surgical stabilisation is not synonymous with early mobilisation ", that was mainly due to the multisystem physiological dysfunction and instability associated with SCI, which may take few weeks to settle. Optimum time for surgical intervention remains a question and it is the opinion of the author that surgery is best done within 4 hours of injury or be deferred later provided that alignment of the spine is corrected and maintained by traction in case of cervical spine injury and bed rest (postural reduction) in thoracic injuries, this is in addition to the standard supportive measures aimed at maintaining adequate cord perfusion and oxygenation [20-30].

\section{High Dose Methyl Prednisolone}

Since the publication of the National Acute spinal Cord Injuries Study (NASCIS) II, high dose methyl Prednisolone administration in the first 8 hours became a standard treatment for the acutely injured spinal cord. Evidence is now accumulating that there is no appreciable functional improvement after such treatment despite a modest improvement in motor scale, in addition it has been shown that the study itself contain statistical artefacts. Although steroids continue to be given to patients with spinal cord injury in many institutions, evidence of deleterious effects continues to accumulate. This controversy led to surgeons having to administer the drug for fear of litigation rather than due to a belief in improved clinical outcomes. After critical evaluation of the data available it is concluded that there is no sufficient evidence to support the use of MP in acute SCI [30-45].

\section{Spinal Decompression in Acute SCI}

It has been shown that many incomplete SCI patients, neurologically \& functionally improve after conservative treatment and / or surgical stabilisation only without decompression of a traumatic spinal stenosis. Also literature show that closed or open reduction of dislocated facets in case of cervical spine offers a satisfactory decompression especially in the first few hours after injury, with good clinical outcome (in some series up to $85 \%$ ) in terms of neurological improvement. After critical analysis of the available literature, there is clearly no correlation between the percentage canal encroachment and the extent of neurological deficit, also neurological recovery does not correlate with canal decompression in acute trauma of the spinal cord. Neurological 
decompression and stabilisation, however is indicated in cases of neurological deterioration due to epidural collection or inability to maintain spinal alignment [45-55].

\section{Conclusion}

Management of acute SCI is still sub-optimum in many areas due to the relative rarity of such devastating injury; more high quality research is required to arrive at consistent standards of care or protocols of management. It is the opinion of the author that the need arises for the creation of spinal injuries centres covering a wide population area, with an integrated multi-disciplinary input and a comprehensive care routine of management from the early hours of injury; this will undoubtedly solve the competency issue of the treating team.

\section{References}

1. Alho A (1994) Operative treatment as a part of comprehensive care for patients with injuries of the thoracolumbar spine. Paraplegia 32(8): 509- 516.

2. Barbeau H, Lodouceur M, Norman K, Pepin A, Leroux A (1999) Walking after spinal cord injury: evaluation, treatment and functional recovery. Arch phys med rehabil 80(2): 225-233.

3. Bracken MB, Shephard MJ, Collins WF, Halford TR, Young W, et al. (1990) A randomised controlled trial of methyl prednisolone or Naloxone in the treatment of acute spinal cord injury, results of the second national acute spinal cord study. N Eng J Med 332(20): 1405-1411.

4. Bracken MB, Shepherd MJ, Halford TR, Leo Summers L, Aldrich EF, et al. (1997) Administration of Methyl prednisolone for 24 or 48 hours or Tirilizad Mesylate for 2448 hours in the treatment of acute spinal cord injury: results of the third national acute spinal cord injury randomised controlled trial. JAMA 277(20): 1597-1604.

5. Bravo P, Labarta C, Alcaraz MA, Mendoza J, Vardu A (1993) Outcome after vertebral fractures with neurological lesion treated either surgically or conservatively in Spain. Paraplegia 31(6): 358-366.

6. Burns SP, Golding DG, Rolle WA, Graziani V, Dittunno JF (1997) Recovery of ambulation in motor incomplete tetraplegia. Arch phys med rehabil 78(11): 1196-1172.

7. Delamarter RB, Sherman J, Carr JB (1995) Pathophysiology of spinal cord injury, recovery after immediate and delayed decompression. JBJS 77(7): 1042-1049.

8. Dickson R (1992) Spinal injuries: early surgical treatment. Paraplegia 30: 43-45.

9. Dimar JR, Glassman SD, Raque GH, Zhang YP, Shields CB (1999) The influence of spinal canal narrowing and timing of decompression on neurologic recovery after spinal cord contusion in a rat model. Spine 24(16): 1623-1633.

10. Dittunno JF, Stover SL, Freed MM, Ahn JH (1992) Motor recovery of the upper extremities in traumatic quadriplegia: a multicenter stud. Arch Phys Med Rehabil 73(5): 431-436.

11. Ditunno John F (1999) Predicting recovery after spinal cord injury, a rehabilitation imperative. Arch phys med rehabil 80(4): 361-364.
12. Eck JC, Nachtigall D, Humphreys SC, Hodges SD (2006) Questionnaire survey of spine surgeons on the use of methylprednisolone for acute spinal cord injury. Spine 31(9): E250-E253.

13. Fehlings MG, Perrin RG (2006) The timing of surgical intervention in the treatment of spinal cord injury: A systematic review of recent clinical evidence. Spine 31(11): S28-S35.

14. Fehlings MG, Sekhon LH, Tator C (2001) The role \& timing of decompression in acute spinal cord injury: what do we know? What should we do? 26(24): S101-S110.

15. Fehlings MG, Tator CH (1999) An evidence based review of decompressive surgery in acute spinal cord injury: rationale, indications, and timing based on experimental and clinical studies. J Neurosurg 91(1 Suppl): $1-11$.

16. Frampton AE, Eynon CA (2006) High dose methyl prednisolone in the immediate management of acute, blunt spinal cord injury: what is the current practice in emergency departments, spinal units in the UK? Emerg Med J 23(7): 550-553.

17. Frankel H, Michailis L, Peaslack V (1973) Closed injuries of the cervical spine and spinal cord: results of conservative treatment of extension rotation injuries of the cervical spine with tetraplegia. Paraplegia 2931(19): 52-55.

18. Frankel HL, Hancock DO, Hyslop G, Melzak J, Michaelis LS, et al. (1969) The value of postural reduction in the initial management of closed spinal injuries of the spine with paraplegia and tetraplegia. Paraplegia 7(3): 179-192.

19. Hall ED, Springer JE (2004) Neuroprotection and acute spinal cord injury: A reappraisal. NeuroRx 1 (1): 80-100.

20. Heiden JS, Weis MH, Rosenberg AW, Apuzzo MJ, Kurze T (1975) Management of cervical spinal cord trauma in southern California. J neurosurg 43(6): 732-736.

21. Hickey R, Albin MS, Bunegin L, Gelineau J (1986) Autoregulation of spinal cord blood flow: is the cord a microcosm of the brain? Stroke 17(6): 1183-1189.

22. Hurlbert RJ, Hamilton MG (2008) Methyl Prednisolone for acute spinal cord injury, 5-year practice reversal. Can J NeurolSci 35(1): 41-55.

23. Hurlbert RJ (2006) Strategies of medical intervention in the management of acute spinal cord injury. Spine 31(11 Suppl): S16-S21.

24. Johnson J, Leatherman K, Holt R (1983) Anterior decompression of the spinal cord for neurological deficit Spine 8(4): 396-405.

25. Katoh S, El Masry WS, Jaffray D, Mc Call IW, Eisenstein SM, et al. (1996) Neurologic outcome in conservatively treated patients with incomplete closed traumatic cervical spinal cord injuries. Spine 21(20): 2345-2351.

26. Katoh S, El Masry WS (1995) Motor recovery of patients presenting with motor paralysis and sensory sparing following cervical spinal cord injuries. Paraplegia 33(9): 506-509.

27. Kinoshita H, Nagata Y, Ueda H, Kishi K (1993) Conservative treatment of burst fractures of the thoracolumbar and lumbar spine. Paraplegia 31(1): 58-67.

28. Kirshblum SC, O'Connor KC (1998) Predicting neurologic recovery in traumatic cervical spinal cord injury. Arch phys med rehabil 79(11): 1456-1466. 
29. Kronvall E, Sayer FT, Nilsson OG (2005) Methylprednisolone in the treatment of acute spinal cord injury has become more and more questioned. Lakartidningen 102(24-25): 1887-1888.

30. Lee HC, Cho DY, Lee WY, Chuang HC (2007) Pitfalls in treatment of acute cervical spinal cord injury using high dose methyl Prednisolone: a retrospective audit of 111 patients. Surgneurol 68(suppl 1): S37-S41.

31. Little JW, Dittunno JF, Stiens SA, Harris RM (1999) Incomplete spinal cord injury: Neuronal mechanisms of motor recovery and hyperreflexia. Arch phys med rehabil 80(5): 587-598.

32. Menter RR, Bach J, Brown DJ, Gutteridge G, Watt J (1997) A review of the respiratory management of a patient with high level tetraplegia. Spinal Cord 35: 805-808.

33. Murphy KP, Opitz JL, Cabanela ME, Ebersold MJ (1990) Cervical fractures and spinal cord injury: outcome of surgical and non-surgical management. Mayo Clin Proc 65(7): 949-959.

34. Nockels RP (2001) Non-operative management of acute cord injury Spine 26(245): S31-S27.

35. OnzeLeiveVrouweGasthuis Amsterdam (1988) Remodelling of the spinal canal after burst fracture, a prospective study of two cases.

36. Petitejean M, Mousselard H, Pointillart V, Lassie P, Senegas J, et al. (1995) Thoracic Spinal Trauma and Associated Injuries: Should Early Spinal Decompression Be Considered? J Trauma-injury Infection \& critical care 39(2): 368-372.

37. Pollard ME, Apple DF (2003) Factors associated with improved neurologic outcomes in patients with incomplete tetraplegia. Spine 28(1): 33-39.

38. Poynton AR, O'farrell DA, Shannon F, Murray P, Mcmanus F, et al. (1997) An evaluation of the factors affecting neurological recovery following spinal cord injury. Injury 28(8): 545-548.

39. Qian T, Guo X, Levi AD, Vanni S, Shebert RT, et al. (2006) High-dose methylprednisolone may cause myopathy in acute spinal cord injury patients. Comment in: Spinal Cord 44(4): 263-264.

40. Rechtine Glenn Non-operative treatment of thoracic and lumbar fractures, old Oswestrian club lecture.

41. Rechtine GR, Cahil DW, Chin AM (1999) Treatment of thoracolumbar trauma-comparison of complications of operative versus non-operative treatment. JBJS 82B(suppl. II): 161-2000.

42. Rosenberg N, Lenger R, Weisz I, Stein H (1997) Neurological deficit in a consecutive series of vertebral fracture patients with bony fragments within the spinal canal. Spinal Cord 35(2): 92- 95.
43. Rosenfeld JF, VaccaroAR, Albert TJ, Klein GR, Cotler JM (1998) The benefits of early decompression in cervical spinal cord injury. Am J Orthop 27(1): 21-28.

44. Roth EJ, Nussbaum SB, Berkowitz M, Primack S, Oken J, et al. (1995) Pulmonary function testing in spinal cord injury: correlation with vital capacity Paraplegia 33(8): 454-457.

45. Sapkas GS, Papagelopoulos PJ, Papadakis SA, Themistocleous GS, Stathakopoulos DP, et al. (2003) Thoracic spinal injuries: Operative treatments and neurologic outcomes. Am J Ortho 32(2): 85-88.

46. Sayer FT, Kronvall EN, Nilsson OG (2006) Methylprednisolone treatment in acute spinal cord injury: The myth challenged through structured analysis of published literature. Spine J 6(3): 335-343.

47. Short DJ, El Masry WS, Jones PW (2000) High dose methyl prednisolone in the management of acute spinal cord injury- a systematic review from a clinical perspective. Spinal Cord 38(5): 273-386.

48. Sorensen P (2008) High dose methylprednisolone in acute spinal cord injury. Ugeskrift for Laeger 170(5): 315-317.

49. Tator CH, Duncan VE, Edmonds VE, Lapczak LI, Andrews DF (1997) Comparison of surgical and conservative management in 208 patients with acute spinal cord injury. Can J Neurol Sci 14(1): 60-69.

50. Tsutsumi S, Ueta T, Shiba K, Yamamoto S, Takagishi K (2006) Effects of the second national acute spinal cord injury study of high dose methyl prednisolone therapy on acute cervical spinal cord injury - results in spinal injuries centre. Spine 31(26): 2992-2996.

51. Vaccaro AP, Daugherty JR, Sheehan TP, Dante SJ, Cotler JM, et al. Neurologic Outcome of Early Versus Late Surgery for Cervical Spinal Cord Injury Spine 22(22): 2609-2613.

52.Wang D, Teddy PJ, Henderson NJ, Shine BS, Gardner BP (2001) Mobilisation of patients after spinal surgery for acute spinal cord injury Spine 26(20): 2287-2282.

53. Waters RL, Meyer PR, Adkins RH, Felton D (1999) Emergency, acute and surgical management of spine trauma. Arch phys med rehabil 80(11): 1383-1390.

54. Wilmot CB, Hall KM (1986) Evaluation of the acute management of tetraplegia: conservative versus surgical treatment. Paraplegia 24(3): 148-153.

55. Wilmot CB, Hall KM (1986) Evaluation of acute surgical intervention in traumatic paraplegia. Paraplegia 24(2): 71-76.

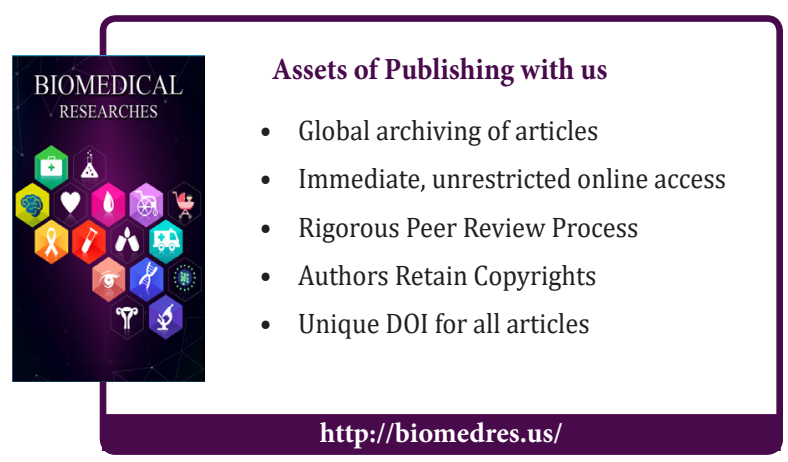

